\title{
Amenable to Reason: Aristotle's Rhetoric and the Moral Psychology of Practical Ethics
}

\begin{abstract}
An Aristotelian conception of practical ethics can be derived from the account of practical reasoning that Aristotle articulates in his Rhetoric and this has important implications for the way we understand the nature and limits of practical ethics. An important feature of this conception of practical ethics is its responsiveness to the complex ways in which agents form and maintain moral commitments, and this has important implications for the debate concerning methods of ethics in applied ethics. In particular, this feature enables us to understand casuistry, narrative, and principlism as mutually supportive modes of moral inquiry, rather than divergent and mutually exclusive methods of ethics. As a result, an Aristotelian conception of practical ethics clears the conceptual common ground upon which practical ethicists can forge a stable and realistic selfunderstanding.
\end{abstract}

\section{U} NLIKE ITS MORE theoretical counterparts, philosophical ethics and political philosophy, practical ethics is a creature of non-ideal circumstances. In part, this is because one of its fundamental goals is to facilitate understanding about issues that may arise within specific social or professional settings, but which involve value judgments that are not the special province of any technical discipline or profession. As a result, practical ethics seeks to engage the moral commitments of persons who may differ widely in their social and economic backgrounds, levels of education, and occupations and interests, in order to facilitate change through the free exchange of reasons. A fundamental question of practical ethics, therefore, concerns how best to conduct a process of reflective deliberation in which people can share and evaluate reasons that warrant undertaking one moral commitment rather than another in a way that will translate into genuine change. 
This question is also fundamental to Aristotle's Rhetoric, and, I will argue, the account of practical moral inquiry elaborated there can provide an important model for practical ethics. In particular, I will argue that a unique virtue of this model is its responsiveness to the complex ways that people form and maintain moral commitments. Because it embodies a robust moral psychology, this model enables individuals to appreciate how different approaches to practical reasoning can help make their moral commitments more amenable to change through reasoned reflection. In closing, I will suggest that taking issues of moral psychology seriously in practical ethics, as Aristotle does, highlights important practical differences between contemporary methods of ethics such as principlism, casuistry, and narrative. More importantly, however, I will argue that a proper understanding of these differences enables us to treat such disparate methods as mutually supportive modes of moral reasoning that can be integrated together under a more unified conception of practical ethics.

\section{REASONS, EMOTIONS, AND MORAL COMMITMENTS}

Aristotle's moral psychology has been the subject of renewed interest among some contemporary moral philosophers because of its unique sensitivity to the important cognitive role of the emotions in human understanding. Aristotle describes the emotions as "all those feelings that change people so as to alter their judgments and [that] are accompanied by distress and pleasure-for example anger, pity, fear, and the like, and their opposites" (Rhetoric 1378a22-24). ${ }^{1}$ When we are pleased and friendly, say, "our judgments are not the same as when we are pained and hostile" (Rhetoric 1356a14-17) because our affective orientation to a case can "make things appear altogether different, or different in degree" (Rhetoric 1378a1-5). The point is not that the emotions can distract or blind us and that they must therefore be calmed in order for reason to function properly. Rather, the point is that their role is more extensive and positive. Because emotional dispositions are propensities to respond to certain features of the world, the shape of individuals' emotional states can influence not only the features of the world that they perceive to be morally salient, but also their evaluative attitude toward those features. As a result, the shape of one's affective dispositions can have an important role in one's ability, or inability, to perceive something as having a particular moral salience. 
Because emotions can provide such a cognitive window to the normative world, Aristotle argues that engaging in public deliberation about common moral questions requires not only (1) "the ability to reason logically, but also [(2)] the ability to understand human character and goodness in their various forms and [(3)] to understand the emotions-that is, to name them and describe them, to know their causes and the way in which they are excited" (Rhetoric 1356a22-25). Aristotle is keenly aware that, although we strive to shape ourselves and our conduct around considerations of reason, reason is not the sole source and arbiter of our moral commitments. Even where the goal is to effect change through shared deliberation and the exchange of reasons, Aristotle warns against blithely assuming that all of our moral commitments are what I will call "reasoned commitments."

By a reasoned commitment, I mean a commitment that stems from an agent's belief that she possesses reasoned grounds that support a particular moral commitment such that if those grounds were successfully challenged she would give up, or at least seriously question, that commitment. A reasoned commitment is one that an individual holds because and only insofar as she believes that she can rationally justify it. In some respects, these are the philosopher's favorite sort of moral commitment because they are derived from, and immediately responsive to moral arguments. In ideal theory we treat agents as forming and maintaining primarily reasoned commitments. But in non-ideal theory we must recognize that there are other distinct, though closely related, sources of commitment and that it may take time and effort to engage them in a way that will make them responsive to change through reasoned reflection.

Consider a brief example from the novel Huckleberry Finn. As Huck journeys down the Mississippi with the escaped slave Jim, he is torn between conflicting moral commitments. On the one hand, Huck has internalized the norms of his ambient culture according to which Jim is property that rightly belongs to someone else. In light of these norms, Huck feels guilty for helping Jim escape and believes that what he is doing is wrong. At the same time, however, part of the reason that he does not turn Jim in is that he cannot help but perceive Jim as a fellow person. On an emotional level, Jim is a someone for Huck, and, even though it remains imperfect and difficult for Huck himself to understand, it is this attitude toward Jim that prevails.

The way that Huck responds to Jim on an emotional level is an example of what I will call an affective commitment. These are moral com- 
mitments that grow out of the way people respond to certain situations in light of their particular emotional and affective dispositions-their particular psychological economy. They are also the sort of commitments one can have before one is capable of offering a justification for them. Nevertheless, they are not irrational. For Aristotle, the emotions are themselves partly constituted by beliefs or propensities to believe certain things about the object of the emotion. As a result, emotions are cognitively rich in the sense that they are structured by evaluated attitudes that can be assessed for their subtlety, sensitivity, and reasonableness. In some cases, reflecting on the evaluative attitudes that structure an emotional response can lead one to adopt beliefs that are more subtle and more reasonable than one's previously considered view. Alternatively, when the attitudes that structure an emotional response are seen upon reflection to be unreasonable or overblown, this may lead one to revise those attitudes and, in doing so, change one's propensity to view the world in the way that elicited that response. In both cases, uncovering and reflecting on the evaluative attitudes that structure our emotional responses is an important means of reconciling our affective and reasoned commitments.

In Huck's case, his affective commitment conflicts with what I will call a social commitment. These are commitments that are internalized because they are inherent in normative structures-be they familial, cultural, institutional, professional, or otherwise-that have shaped a person's conduct. Part of the novel's drama lies in Huck's own awkward attempts to understand the conflict between a way of thinking about Jim that he takes over from his broader cultural milieu and the perception of Jim's humanity and kinship that emerges as they travel together. Furthermore, Huck is a poor moral philosopher; his awareness of the nature and source of this conflict is largely inarticulate and sometimes comically dim. As readers, however, the effect of participating in Huck's struggle is that we are encouraged to undertake the task of examining the norms and values that underwrite both of these commitments and to subject them to critical scrutiny. In this process of discovery and examination, the hope is that we will develop a reasoned commitment that is articulate and informed by what is best in Huck's own affective commitments to Jim.

The point of this example is simply to illustrate three possible sources of moral commitment that can interrelate and overlap or diverge in a variety of complex ways. For Aristotle, having an understanding of these possible interrelations is important because it bears on one's ability to reason with others in a public setting. In particular, it provides a reason to 
prefer approaches to moral reasoning that recognize and take steps to accommodate this complexity because they enable us to deliberate in a way that will make such possibly diverse commitments more amenable to change though reasoned reflection.

\section{ENGAGING OVERLAPPING COMMITMENTS}

Even in Aristotle's day, the term "rhetoric" had acquired unsavory connotations, and Aristotle himself castigates popular treatises on the subject for focusing entirely on how to avoid addressing "the facts" of a case (Rhetoric 1354a18). According to Aristotle, they leave out what he sees as the "substance" of rhetorical persuasion (Rhetoric 1354a14-15), namely, instructions on how to construct arguments that are "demonstrative and worthy of belief" (Rhetoric 1377b22- 24). In contrast, Aristotle articulates a conception of rhetoric as a truth seeking, reason giving enterprise that aims at providing a form of argumentative demonstration (apodexis tis) "since we are most fully persuaded when we consider a thing to have been demonstrated" (Rhetoric 1355a4-6). This conception of public moral inquiry is particularly important for practical ethics because of its emphasis on employing methods of deliberation that are shaped to suit the special challenges of reasoning under non-ideal circumstances.

To begin with, Aristotle recognizes that the parties to practical deliberations are not simply agents of ideal theory. Rather, they may differ widely in their familiarity with formal reasoning, in their interests and abilities, level of education and emotional availability. Because of this, Aristotle explicitly excludes the use of the philosophically refined premises of special disciplines such as philosophical ethics or politics from practical deliberations (Rhetoric 1358a21-26, 1359b2-18). Instead, practical arguments must draw endoxa, views that are widely held, that are generally reputable, or that are very plausible in their own right. ${ }^{2}$ His reasons for setting these restrictions are important, and after articulating them I will argue that similar concerns inform some contemporary approaches to practical ethics.

First, Aristotle recognizes that the parties to practical deliberation must make an effort to present reasons to one another in a way that is accessible and enhances their understanding of the issue at hand. He also recognizes that such persons frequently do not have the philosopher's facility with specialized concepts of ethical theory and that the project of bringing about such a familiarity cannot be achieved within the constraints of many practical settings (Rhetoric 1355a26-28, 1357a1-13). In this re- 
spect, Aristotle is aware of a problem that many practical ethicists have encountered with more robustly philosophical or "top down" approaches to applied ethics. Namely, in the clinic, the boardroom, or the council chamber, overly formal and esoteric approaches to ethical issues frequently alienate some of the very parties to practical deliberation whose cooperation and understanding are necessary in order to bring about real change.

Second, and perhaps more importantly, Aristotle recognizes that even if the parties to such deliberations understand the premises of more theoretical disciplines in an intellectual way, this understanding may not be deep enough to link them to more diffuse and motivationally vital moral commitments. To the extent that arguments that rely on such theoretical premises lack a purchase on the breadth of a person's moral commitments, they may fail to win the agent's assent. Alternatively, they may win such assent but lack motivational force or fail to effect a broader change in the agent's cognitive and affective orientation to the appropriate range of practical situations. In this case, not only might the agent's affective commitments remain a problem in some range of cases, they might even function as a source of resistance to a genuinely open evaluation of such reasons.

A brief example illustrates some of these possibilities. Doctor Smith is a respected surgeon who is highly sensitive to the gravity of his work and who has always felt the immensity of operating on other living beings. $\mathrm{He}$ comports himself with a degree of quiet assurance, confidence, and control that puts both his patients and his colleagues at ease, and he is constantly trying to improve his medical expertise. As a result he is involved in testing a number of innovative new surgical procedures. It is often the case, however, that Smith does not take his patients through a rigorous process of informed consent when enrolling them in a trial of such new procedures. In fact, he usually does not tell his patients that there are medically viable alternatives with a history of proven efficacy. When asked about this, he responds that he would not give his patients anything less than top-notch care and that those who receive the new procedure are receiving this level of care. Yet in the articles he publishes, Smith is forthright about the necessity of quantifying the differences between existing procedures and supposed innovations on the grounds that without hard data one cannot know which procedure is most effective under which circumstances. ${ }^{3}$

On the one hand, there are certain contexts in which Smith admits the lack of scientific evidence that would confirm the superiority of one treat- 
ment modality over another. Within the therapeutic context, however, Smith either denies this fact, or denies that it makes a morally significant difference. For present purposes, I will simply stipulate that this is because Smith cannot both admit that the procedure he is performing may not be the best modality of treatment for the patient's condition and at the same time maintain the level of assurance and confidence that he requires in order to face the immense responsibility of performing surgery on another human being. ${ }^{4}$ As a result, alternatives such as a more robust view of the importance of patient autonomy encounter resistance because they appear to embrace a level of uncertainty that is incompatible with the attitude of assurance and control that he needs in order to operate.

It is important to note that the features of Smith's psychology that underwrite his commitment to paternalistic interactions with his patients may also prevent him from appreciating certain morally salient features of his relationships with those patients. The fact that he is "blind" to such features of these relationships may thus make it easier to embrace arguments or justifications that rationalize this position. However, it may also be the case that Smith is in some sense aware of these features but that he looks for arguments that will justify his position in an attempt to rationalize his attitude of indifference towards them. In any case, although he looks to these arguments to support this commitment, his commitment to these arguments may itself be fairly weak. For instance, if his arguments are seriously challenged, he may simply give them up. Rather than changing his commitment to their conclusion, he may simply look for alternative arguments that he hopes will provide the required justification. If Smith is convinced on a purely intellectual level that medical paternalism is morally problematic, but his underlying affective commitments are left untouched, he may persist in failing to perceive that certain of his interactions with his patients are instances of paternalism.

I offer this case as an extreme example of the way in which overlapping sources of moral commitments can pose a challenge to bringing about change through practical deliberation. This is important because even in less extreme cases the same type of emotional or psychological dispositions that underwrite this sort of affective commitment may also prevent a person from giving open and honest consideration to the merits of persuasive considerations that a potential interlocutor might put forth. For instance, it may be that at the level of particulars one does not recognize certain features of one's interactions with patients as morally salient, and to the extent that this is the case, one might simply disagree with compet- 
ing characterizations of those interactions. Or again, even if there is a sense in which one is aware that these features are morally important, one might nevertheless resist arguments that assign them a particular normative status at a more general level. This is not to say that every interlocutor will necessarily have this kind of response and it is not to say that we should be expected to anticipate which of these responses an interlocutor is likely to exhibit. The point is, rather, that we might have good, practical reasons for preferring a method of moral inquiry that recognizes the possibility of these kinds of responses and takes certain steps to minimize or manage them.

\section{CONSTRUCTING ENTHYMEMES}

Because people frequently come to the table with a variety of existing moral commitments, Aristotle argues that the parties to practical deliberation should try to build their arguments out of considerations that are both to the point and have some purchase on an interlocutor's own belief set or doxastic framework. Aristotle calls such arguments enthymemes, "the most authoritative (kuriotaton) form of persuasion" (Rhetoric 1355a7-8). As Burnyeat (1996) argues, the enthymeme is simply a reasoned argument whose premises consist of enthumema, considerations that might command the interlocutor's assent when reflecting on issues about which there are no deductively conclusive arguments. Enthumema are "considerations for the audience to think about" (Burnyeat 1996, p. 93), considerations that will weigh on one's deliberations about an issue and give rational agents better reason to choose one alternative over another, all things considered.

Aristotle encourages the building of such arguments out of endoxa because these are views that "are accepted by our judges or by those whose authority they recognize" (Rhetoric 1395b30-1396a2). If people are not already in some way committed to such premises, then they are at least disposed to accept them (Rhetoric 1395b10-11). They help to ensure that the parties to practical deliberations comprehend the reasons that are being offered by ensuring that their arguments are built out of materials taken from within their interlocutors' own doxastic framework. The goal is to build as convincing an argument as possible, relying on as many of the interlocutors' commitments as possible, so that the strength of those commitments will be transferred to the argument's conclusion. This is meant to ensure that one's interlocutors not only understand the arguments in question, but that they do so in a way that engages and marshals some of their own broader moral commitments. 
There is an important sense in which principlism can be seen as one more fully elaborated method of constructing these sorts of arguments. Principlists often claim that one attractive feature of their method is its ability to avoid lengthy disagreement at the theoretical level by working with familiar, abstract principles detached from their theoretical moorings. These principles are supposed to be simple enough that ordinary people can grasp both their content and the sense in which they already have some degree of pretheoretical commitment to them. In this sense, principlism tries to meet the condition of working with endoxa. In working together to specify the way in which these principles enliven a particular case, interlocutors group together considerations that weigh on their judgments in a way that is organized and reasoned, but not overly formalistic and esoteric (Rhetoric 1395b22-1396a4). Although more theoretically minded critics of this approach may see this as a philosophical weakness (Gert, Culver, and Clouser 1997), it is a practical strength because it allows moral inquiry to begin from considerations that interlocutors can agree are important and to which they are already committed.

For Aristotle, the enthymeme is the most authoritative of the practical arguments because of its argumentative form. That is, the enthymeme is an informal demonstration of the way that a particular judgment is supported by or follows from more general moral claims. But Aristotle is also forthright about the fact that other methods of moral reasoning may provide more effective means of engaging a person's broader moral commitments. Arguments from example and the use of detailed narratives are thus important methods of moral reasoning in their own right. But Aristotle also recognizes that each of these methods can be used to complement the others in important ways, forging a cognitive and affective link between a person's broader moral commitments, the morally salient features of the issue at hand, and the content of the claims that enthymemes put into a particular argumentative form.

\section{NARRATIVES AND MORAL PERCEPTION}

From an Aristotelian perspective, the careful construction of narratives in ethics is useful because of their ability to flag certain features of a situation as morally salient. Not only can they influence the affective commitments of potential interlocutors by focusing on "details which carry conviction," they can influence reasoned commitments by enabling an agent to see something as a reason (Rhetoric 1417b1-3). Consequently, Aristotle encourages speakers to make the appropriate use of narration 
throughout their arguments in order to bring events before their interlocutor's eyes (Rhetoric 1416b16-1417b20; cf. 1411b22-27). This insight is one that contemporary proponents of narrative have developed in some detail.

For the narrative ethicist, the goal is to construct a narrative that portrays the morally relevant features of a case as they appear within the rich and complex tapestry of meaning that makes up the lives of the relevant agents. The strength of such narratives lies in their ability to bring out the morally salient features of an issue within a concrete setting that is both cognitively rich and directly engaged with a person's affective dispositions. Subtle and carefully crafted narratives can elicit affective responses to features of a case in a way that may itself constitute a judgment about the moral relevance of those features. In cases where an agent does not have strong preexisting commitments, a subtle narrative can help to generate an affective commitment by eliciting a particular evaluation of the case at hand.

In cases where agents already have preexisting moral commitments, narratives can serve to unify those commitments, or to point out conflicts within them. This is particularly true for cases in which an agent's evaluation of a class or kind of activity has been formed through a process of overgeneralizing certain paradigm cases. In Smith's case, for instance, the narrative portrayal of a particular case might provide a compelling, concrete illustration not only of the way in which a patient's broader values are relevant to her choice of treatment modality, but also of the ways in which she is wronged when denied this choice. Perhaps more importantly, this sort of narrative might succeed in making salient the patient's distinctness as an individual in the midst of her own life, with all its richness and complexity. Not only might this depiction help to create a concrete sense of the empowerment that can come with informed participation, but it might free Smith of the underlying idea that the choice of treatment modality is his to make. That is, a well-crafted narrative might help turn his tendency to perceive informed consent as the sharing of uncertainty into a propensity to see informed consent as a way of sharing responsibility for life choices that are ultimately another person's. Regardless of whether such a narrative would lead Smith to revise his original commitment in all cases, it may at least put him in a position to appreciate more deeply the meaning and importance of patient autonomy.

Recognizing the power of narrative is important because creating narratives and telling stories are fundamental forms of shared moral dis- 
course. This is particularly true in medical ethics where the case narrative plays such an important role in practical deliberation. For Aristotle, however, narrative and enthymemetic argument complement each other and should be used together, along with examples drawn from historical or invented situations that can be compared to the case at hand by analogy (Rhetoric 1393a22-1394a18). An important feature of casuistry, therefore, is its ability to exploit both the power of narratives and that of reasoning from analogy.

\section{REASONING FROM CASES}

Where principlism represents the elaboration of a particular method for constructing enthymemes in practical ethics, contemporary casuistry represents a refinement of analogical reasoning and a use of examples that provides a somewhat more complex approach to the possibility of overlapping commitments. One strength of the casuist's approach is that it begins by shifting the practical context of inquiry away from the disputed issue to cases that are less likely to trigger resistance in the interlocutor. That is, in order to come to a judgment about one case, the casuist and her interlocutor begin by searching for paradigm cases that resemble the case at hand, but about whose normative status they can agree. Locating a range of paradigm cases allows the casuist to focus on and highlight certain morally salient features that link the cases together. Depending on the degree of particularity and detail that goes into their elaboration, securing agreement about the normative status of these paradigms can engage an interlocutor's moral commitments at a variety of levels. By utilizing more detailed case narratives, paradigm cases can help harmonize an interlocutor's reasoned, affective, and social commitments regarding the normative status of the morally salient features of those cases. The goal then is to extend the epistemic weight of those commitments into new cases by re-identifying those salient features in cases that move incrementally away from the paradigms and closer to the issue in question. In this way, the strength of the interlocutor's commitments about simple cases can be transferred to more controversial ones.

At its best, the result is that judgments that are operative in those indirect, less controversial contexts can then be exploited in the present context with a force they would not otherwise have had. The cumulative force of these considerations is meant to lead the interlocutor (1) to see the way in which commitments about these other cases are also operative in the context of the controversial case; (2) to reflect critically on the 
grounds of his or her present commitment; and (3) in the best case, to adopt the commitment that is supported by the best reasons.

This is not to say that casuistry can avoid resistance altogether, and it is not to say that every failure to reach agreement in the direct conversational context should be explained as an instance of resistance. Rather, the point is that in focusing the conversation on what particular interlocutors take to be uncontroversial cases, the casuist reinforces and highlights the agents' commitments to the view that certain morally relevant properties have a particular normative status. Because the normative status of the relevant moral properties is worked out in contexts that do not elicit high degrees of resistance, the casuist sometimes is able to undermine or defuse resistance in the direct conversational context in a way that a more direct approach might not.

In shifting the conversation to contexts in which the ethicist and the interlocutor agree, casuistry, like principlism and narrative, attempts to meet the Aristotelian condition of beginning with endoxa. The casuist searches for a context in which the relevant moral properties are salient and in which the interlocutor is, or can easily become, aware of this salience. This approach has the effect of beginning moral inquiry from within the interlocutor's own doxastic framework so that the argument in question is constructed from the interlocutor's own commitments. Doing so helps to ensure that the interlocutor both comprehends and also is committed to the considerations that are marshaled in favor of a judgment about the case at hand. By beginning moral inquiry from cases about which interlocutors can agree, the casuist also sets a more cooperative tone to the inquiry. Reliance on the interlocutor's own commitments helps to ensure that the casuist's arguments will receive a fair hearing and have the appropriate motivational backing to effect a change in the agent's perceptions of the case, and possibly her way of thinking and acting. Regardless of whether casuistry always can bring agents to modify their moral commitments, it can, at the very least, make agents palpably aware of their own conflicting moral commitments. To the extent that they then reflect on the sources of such conflict they may become more receptive to further normative inquiry.

In casuistry, judgments about particular cases are made on the basis of a careful examination of their relationships to a taxonomy of similar cases. As Aristotle seems to recognize, however, the results of this process can themselves serve as premises in enthymemes (Rhetoric 1402b15-18). For instance, an enthymeme may help to clarify the upshot of this process by 
showing how the judgment about the case at hand follows from the recognition that it exemplifies certain morally salient features and the more general claim that those features have a certain moral status. But these two forms of argument can be mutually supportive in another way as well. Just as enthymemes can express the results of examining a critical taxonomy of relevant cases, the careful examination of such cases can bring agents to see how a wider range of their moral commitments are involved in the premises of some enthymeme. In this case, the enthymeme and the process of casuistical reasoning need not lead to the same conclusion. Instead, the claim that certain features of a case have some normative status can be both the conclusion of a process of casuistical reasoning and a major premise in an enthymeme that argues for some other conclusion. Here, the examination of a taxonomy of relevant cases is used to generate a cognitive and affective commitment to a premise of an enthymeme so that the enthymeme itself can transfer the strength of this commitment to its conclusion.

\section{MODES OF MORAL REASONING, NOT METHODS OF ETHICS}

Aristotle's analysis of the foregoing approaches to practical ethics is frequently less detailed and protracted than those of their contemporary proponents. But his remarks about the virtues of combining and nesting them together are still very much to the point. This is because Aristotle treats these approaches as what I have called modes of moral reasoning. That is, he understands them in a way that is fundamentally practical, focusing on the different means by which they highlight the moral salience of important features of a case and how they engage a wider range of a person's moral commitments so that those commitments can be made more responsive to reasoned reflection. This practical orientation is important because it allows one to appreciate substantive differences between these methods by highlighting genuine strengths and weaknesses, while also stressing the sense in which they are ultimately compatible forms of reasoning that can be used to reach a common objective.

This more practical approach is significantly different from one that understands these methods on the model of Sidgwick's methods of ethics. For Sidgwick (1981, p. 17), a method of ethics is "any rational procedure by which we determine what individual human beings 'ought'-or what it is 'right' for them-to do, or to seek to realize by voluntary action." The sort of "procedure" that he has in mind, however, is quite philosophically sophisticated. I might, for instance, believe that the way to settle a par- 
ticular moral question is to generate an account of the highest good for people, then generate an account of the most effective means of realizing that end, so that we may then set about pursuing those means. Utilitarianism is thus a different method of ethics from rational egoism because, although they both take human happiness as their end, the former seeks to achieve the greatest happiness of the greatest number while the latter pursues only individual happiness. Both of these methods are contrasted with what he calls the "intuitional view according to which conduct is held to be right when conformed to certain precepts or principles of Duty, intuitively known to be unconditionally binding” (Sidgwick 1981, p. 3).

For Sidgwick, then, methods of ethics are comprehensive philosophical systems derived from substantive metaethical positions concerning the nature and source of value, the way in which values are known, and other such robustly philosophical claims. Now, it is often the case that principlism, casuistry, and narrative ethics are represented as alternative and mutually exclusive methods of ethics. Sometimes these methods are treated as divided over substantive issues in moral epistemology. This happens when one understands casuistry as embodying the view that "moral knowledge is essentially particular"(Jonsen 1998, p. 330) while understanding principlism as beginning with intuitions of general moral principles that lay out prima facie duties. As such, the two would be incompatible methods of ethics, because casuistry, in this instance, is thought to depend on the view that our knowledge of more general moral claims must be derived from and remain beholden to our considered judgments about particular cases whereas principlism supposedly allows for knowledge of general moral principles, the relationships between which simply have to be worked out in the face of particular situations (Beauchamp and Childress 1994, pp. 102-11). Alternatively, both methods are sometimes distinguished from a narrative ethics that sees the meaning of moral claims as depending on their place within certain master-narratives that determine the values that define individuals as members of some community. ${ }^{5}$

In the same way, these positions are often treated as following from incompatible conceptions of moral justification as well. On this view, principlism takes a moral claim to be justified when it is shown to follow from the requirements of an ethical principle in conjunction with the facts of a particular case. Casuistry, in contrast, takes a moral claim to be justified when it coheres with the set of authoritative judgments embodied in a considered taxonomy of relevantly similar cases. Finally, narrative eth- 
ics sees justification as relative to the master-narratives that define the moral character of a community.

Against this backdrop, principlism, casuistry, and narrative are portrayed as elements of divergent and mutually exclusive comprehensive theories of value so that any choice between them requires one to take a stand on these more general positions. In turn, this fosters the appearance of an increasingly fragmented field in which the traditional disputes of philosophical ethics are simply recapitulated by the growing number of divergent methodological frameworks.

The Aristotelian conception of practical ethics that I have elaborated provides a much needed antidote to this view by providing a framework for understanding the value of these methods as approaches to moral reasoning that can be evaluated independently of such substantive philosophical questions. Because of their different practical strengths, and the fact that they can be nested together in subtle ways, there is no reason to think that these approaches to moral inquiry cannot be reconciled with a variety of positions in higher-level philosophical ethics.

I submit that this insight is already latent in the way that many practical ethicists approach these different argumentative tools. Consider, for instance, that proponents of each of these views now seem to be converging on the endorsement of similar varieties of reflective equilibrium. ${ }^{6}$ This consensus runs so deep, in fact, that in the minds of many the very idea of constructing a moral theory is synonymous with bringing particular and more general moral judgments into a state of reflective equilibrium. This trend toward convergence illustrates that the choice between these modes of moral inquiry is underdetermined by one's metaethical commitments because, simply as approaches to moral argumentation, they are consistent with a variety of such views. Beauchamp and Childress (1994, p. 103) now seem to embrace this fact openly, and they have so revised their conception of principlism that it might now be referred to as methodological eclecticism. For similar reasons, critics of casuistry (Arras 1991, pp. 46-47) have proposed combining the strengths of its attention to particular cases with the theoretical robustness of certain neo-Kantian approaches to ethics.

The fact that there are important practical, and in an Aristotelian sense rhetorical, differences between these approaches to moral reasoning takes on increased importance, then, because these remain the most relevant criteria for evaluating their use in practice. This philosophically deflationary approach thus clears a kind of common ground on which practi- 
cal ethicists may be able to build a more unified, and practically accurate, self-conception.

Perhaps the most provocative and important feature of this Aristotelian conception of practical ethics is the way it attempts to embrace a more practical orientation to moral deliberation without abandoning reasoned argumentation for mere persuasion. This can be difficult to comprehend because of the novel way that Aristotle understands practical and philosophical ethics as different faces of a shared search for moral value (London, forthcoming (a)). One must not forget, for example, that both philosophical and practical ethics begin with endoxa and require the exercise of the same powers of discrimination and perception. For Aristotle, however, the goal of philosophical ethics is to move "from what is known to us, to what is most knowable in itself" (Nicomachean Ethics 1095b110 ) by showing how such common intuitions give rise to certain puzzles and then articulating a philosophically compelling account of moral value that can both solve them and clarify the aspect of truth contained in those original intuitions.

In rhetoric, by contrast, the goal is not to raise puzzles for our intuitions in order to refine them into a consistent theory. It is, rather, to use the modes of moral inquiry I have described here to bring out those elements of truth in their particularity and marshal them in support of specific moral judgments in light of the facts of a particular case. In practical settings Aristotle thinks it is less difficult to ensure that people are committed to the conclusions of arguments derived from endoxa than to ensure that they (1) understand and (2) are committed to conclusions that are derived from the theory that results from the clarification and analysis of such endoxa so that (3) those refined propositions can then be used to inform our understanding of particular cases. Practical arguments are still seeking truth, however, because they are derived from and beholden to the same considered perceptions of value as are the theories that result from their refinement in philosophical reflection. ${ }^{7}$ Clearly this is a position that requires a more detailed defense in its own right (see London, forthcoming (a)) but these cursory remarks should provide some indication of the degree to which Aristotle is committed to the independent legitimacy of the practical search for value that we, as non-ideal agents, undertake together.

\section{CONCLUSION}

The challenge of practical ethics, from an Aristotelian point of view, is to influence the judgments of other agents by sharing reasons in a manner 
that makes those considerations as vivid, and motivationally compelling as possible. Because the practical ethicist is trying to justify claims to actual moral agents, she requires an adequate grasp of the complex ways in which such agents acquire and maintain their moral commitments and an understanding of means of making those commitments as receptive to reasoned considerations as possible. In this regard, I have sketched a conception of practical ethics drawn from Aristotle's Rhetoric that provides a framework within which what are sometimes viewed as mutually exclusive methods of ethics can be seen as compatible and complementary modes of moral inquiry with different rhetorical strengths.

Earlier versions of this paper were presented at the American Society for Bioethics and Humanities and the Philosophy Departments at Michigan State University, the University

of Tennessee, West Chester University, and the University of North Florida. I thank the members of those audiences for their helpful comments. I also thank John Arras, Mark Kuczewski, and Tracy E. London for their many kind criticisms.

\section{NOTES}

1. Aristotle's works are cited by the standard page numbers of Bekker's edition of the Greek text. These numbers should appear in the margins of any reliable translation. I have relied on the translations in Barnes (1984).

2. On endoxa see Cooper (1999a \& b) and Irwin (1996).

3. Brewin (1982) argues that there is no need to solicit informed consent from research subjects on the grounds that randomized trials are not really research. At one point, he claims: "A doctor who contributes to randomized treatment trials should not be thought of as a research worker, but simply as a clinician with an ethical duty to his patients not to go on giving them treatments without doing everything possible to assess their true worth." Appelbaum and colleagues (1987) cite this as an extreme case of the way in which some physicians resist engaging in the informed consent process because it involves "confessing uncertainty over the best approach to treatment."

4. Katz (1984) explores the way in which a variety of social and psychological forces influence the doctor-patient relationship, including "the need to appear authoritative, the importance of hiding uncertainties from patients, the need to view patients as incompetent to participate in decision making, and the belief that patients' welfare depends on patients' trusting doctors' capacities to know what is in the patients' best interests" (pp. 149-50). He refers to the manifestations of these influences as instances of countertrans- 
ference, broadening the concept to include not only physicians' personal conduct, but also "their deeply ingrained professional attitudes toward patients" (p. 149).

5. See, for instance, Burell and Hauerwas (1977). For criticisms of their view, see Arras (1997).

6. It has been argued that if one looks beyond the theoretical language of casuistry and principlism to their treatment of ethical principles, there turns out to be "no appreciable methodological difference" between them (Kuczewski 1998, p. 520; see also 1997).

7. The view of the relationship between the starting points of ethics and rhetoric that I articulate here is supported by Irwin (1996) and Cooper (1999b). For two different views of the role of theory in moral deliberation in Aristotle's ethical works, see London (forthcoming (b)).

\section{REFERENCES}

Appelbaum, Paul S.; Roth, Loren H.; Lidz, Charles W.; et al. 1987. False Hopes and Best Data: Consent to Research and the Therapeutic Misconception. Hastings Center Report 17 (2): 20-24.

Arras, John D. 1991. Getting Down to Cases: The Revival of Casuistry in Bioethics. Journal of Medicine and Philosophy 16: 29-51.

- 1997. Nice Story, But So What? In Stories and Their Limits, ed. Hilde Lindemann Nelson, pp. 65-88. New York: Routledge.

Barnes, Jonathan. ed. 1984. The Complete Works of Aristotle. Princeton, NJ: Princeton University Press.

Beauchamp, Tom L., and Childress, James F. 1994. Principles of Biomedical Ethics. $4^{\text {th }}$ ed. New York: Oxford University Press.

Brewin, Thurston B. 1982. Consent to Randomized Treatment. The Lancet 2: 919-21.

Burell, David, and Hauerwas, Stanley. 1977. From System to Story: An Alternative Pattern for Rationality in Ethics. In Knowledge, Value and Belief, ed. H. T. Engelhardt, Jr., and Daniel Callahan, pp. 111-52. Hastings-on-Hudson, NY: Hastings Center.

Burnyeat, M. F. 1996. Enthymeme: Aristotle on the Rationality of Rhetoric. In Essays on Aristotle's Rhetoric, ed. Amelie Oksenberg Rorty, pp. 88-115. Berkeley: University of California Press.

Cooper, John. 1999a. Aristotle on the Authority of Appearances. In Reason and Emotion, pp. 281-91. Princeton, NJ: Princeton University Press.

- 1999b. Ethical-Political Theory in Aristotle's Rhetoric. In Reason and Emotion, pp. 390-405. Princeton, NJ: Princeton University Press. 
Gert, Bernard; Culver, Charles M.; and Clouser, K. Danner. 1997. Bioethics: A Return to Fundamentals. New York: Oxford University Press.

Irwin, T. H. 1996. Ethics in the Rhetoric and in the Ethics. In Essays on Aristotle's Rhetoric, ed. Amelie Oksenberg Rorty, pp. 142-74. Berkeley: University of California Press.

Jonsen, Albert, and Toulmin, Stephen.1988. The Abuse of Casuistry. Berkeley: University of California Press.

Katz, Jay. 1984. The Silent World of Doctor and Patient. New York: Free Press.

Kuczewski, Mark G. 1997. Fragmentation and Consensus. Washington, DC: Georgetown University Press.

- 1998. Casuistry and Principlism: The Convergence of Method in Biomedical Ethics. Theoretical Medicine and Bioethics 19: 509-24.

London, Alex John. Forthcoming (a). The Independence of Practical Ethics. Theoretical Medicine and Bioethics.

—. Forthcoming (b). Moral Knowledge and the Acquisition of Virtue in Aristotle's Nicomachean and Eudemian Ethics. The Review of Metaphysics.

Sidgwick, Henry. 1981. The Methods of Ethics. $7^{\text {th }}$ ed. Indianapolis, IN: Hackett Publishing Company. 